Full length article

\title{
Analysis of surface tension driven flow and solidification behavior in laser linear welding of stainless steel
}

\author{
Zhiyong $\mathrm{Li}^{\mathrm{a}, \mathrm{b}}$, Gang $\mathrm{Yu}^{\mathrm{a}, \mathrm{b}, \mathrm{c}, *}$, Xiuli He $\mathrm{H}^{\mathrm{a}, \mathrm{b}, *}$, Shaoxia $\mathrm{Li}^{\mathrm{a}}{ }^{\mathrm{b}}$, Chongxin Tian ${ }^{\mathrm{a}, \mathrm{b}}$, Binxin Dong, \\ ${ }^{a}$ Key Laboratory of Mechanics in Advanced Manufacturing, Institute of Mechanics, Chinese Academy of Sciences, Beijing 100190, China \\ ${ }^{\mathrm{b}}$ School of Engineering Science, University of Chinese Academy of Sciences, Beijing 100049, China

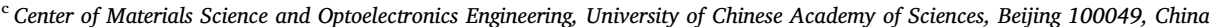

\section{H I G H L I G H T S}

- Qualitative study of the mechanism of surface tension driven flow.

- Analysis of driving forces and driving mechanism.

- Quantitative investigation of surface tension and surface shear stress distribution.

- 3D distribution of solidification parameters.

- Semi-qualitatively prediction of solidified microstructure.

\section{A R T I C L E I N F O}

\section{Keywords:}

Surface tension

Driving force

Fluid flow

Solidification behavior

Additive manufacturing

\begin{abstract}
A B S T R A C T
A transient three-dimensional thermal-fluid-metallurgy model was proposed to study the surface tension driven flow and welding metallurgical behavior during laser linear welding of 304 stainless steel. Numerical simulation and experimental method were both used to investigate the thermal behavior, surface tension driven flow, driving mechanism and solidification characteristics. The temperature related driving force was qualitatively analyzed, and surface tension and surface shear stress were quantitatively studied. Numerical method and dimensional analysis were also carried out to understand the importance of different driving forces, respectively. The metallurgical model was sequentially coupled to the thermal-fluid model to calculate four solidification parameters. Temperature gradient was observed to be much larger at the front of the melt pool due to the effect of thermal conductivity, and decreased from center to the periphery. Both the surface tension and surface tension driven flow were found smaller in the central area. The maximum shear stress may reach $2500 \mathrm{~N} / \mathrm{m}^{2}$ and pushed an intense outward convection. The solidification parameters were used to predict the solidified morphology, and the prediction was well validated by experimental results. The obtained basic conclusions in this work demonstrated that this study of thermal-fluid-metallurgical behavior could provide an improved understanding of the surface tension driven flow and solidification behavior inside the melt pool of welding and additive manufacturing process.
\end{abstract}

\section{Introduction}

With the advantages of high power, high precision, high speed, high efficiency, and low deformation, laser welding has been widely used in the joining of metals, and plays an important role in the fields of aeronautics, automobile, and electronics [1-6]. In laser welding process, the core issue is the thermal behavior and dynamic characteristic of molten pool, which determines the final microstructure and resultant mechanical properties [7-10]. In order to better comprehend the process of laser welding, optimize the process parameters, refine the microstructure and improve the qualities and properties of the laser welded joint, it is necessary to probe the mechanism of heat transfer, fluid flow and solidification characteristics of the melting metal [11-13].

Numerical simulation provides a vital perspective to investigate the capillary and thermal capillary (surface tension) driven fluid flow

\footnotetext{
* Corresponding authors at: Key Laboratory of Mechanics in Advanced Manufacturing, Institute of Mechanics, Chinese Academy of Sciences, Beijing 100190, China and School of Engineering Science, University of Chinese Academy of Sciences, Beijing 100049, China.

E-mail addresses: gyu@imech.ac.cn (G. Yu), xlhe@imech.ac.cn (X. He).
} 


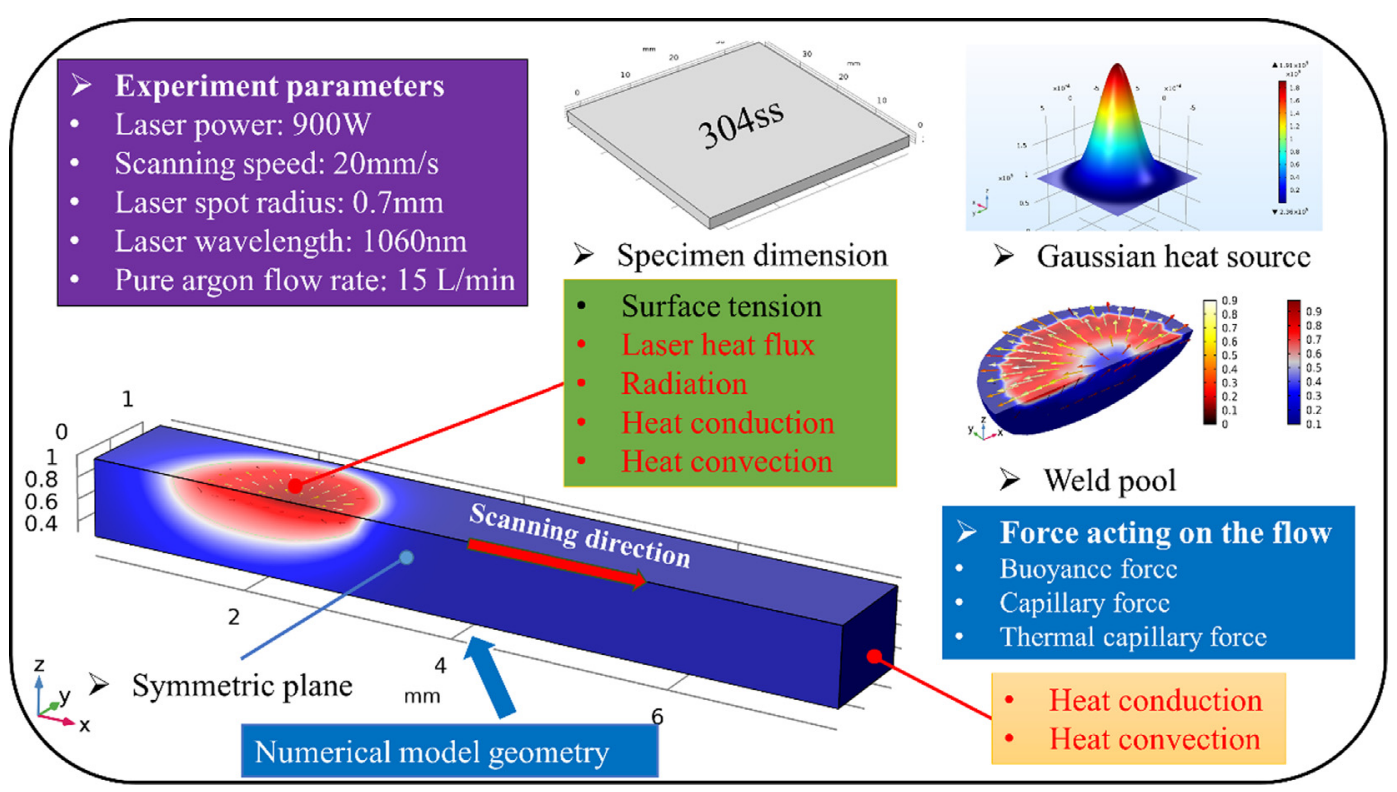

Fig. 1. Schematic diagram for the numerical model.

(Marangoni convection), however, incorporating the accurate driving mechanism with thermal behavior inside the melt pool is one of the great challenges in welding model. But, it is necessary to study the surface tension driven flow quantitatively to deeply understand the heat and mass transfer process and the related solidification characteristics $[14,15]$.

Heat transfer and fluid flow have been the subject in many areas, especially in welding [16,17] and additive manufacturing [18,19]. Some important progress has also been made on the heat transfer and driven mechanism. He at al [20] studied the effect of Marangoni convection generated by surface tension during laser spot welding, and introduced the Peclet number to illustrate the different heat transfer mechanism, and they also concluded that convection was the dominant mechanism when the melt pool reached steady condition. Bahrami et al [21] investigated the convection driven mass transfer during GTA welding of dissimilar metals. It was found that the surface tension driven flow was mainly determined by the temperature derivative and concentration derivative. Mukherjee et al [22] developed a three-dimensional model to study the heat transfer and fluid flow in additive manufacturing. They found that convection was the main heat transfer mechanism and simplified heat conduction calculations would over predict the peak temperature and temperature gradient in the liquid pool.

Although some major achievements on thermal behavior and surface tension driven fluid have been made for the study of melt pool in many manufacturing areas, the relationship between temperature field and flow characteristics is mostly explained by some non-dimensional number, such as the Peclet number and Marangoni number. In other words, the driven mechanism has not been analyzed quantitatively, which is vital to comprehend the convection process accurately [20]. Besides, the solidification parameters obtained from the transient thermal analysis, which have great effect on the final solidified microstructure and mechanical properties, have also received increasing research interest recently. Li et al [23] studied the effect of heat input on the solidification characteristics, and it was observed that cooling rate (GR) was much more sensitive to the heat input than the morphology parameter (G/R). Wei et al [24] investigated the relationship between thermal behavior and microstructure evolution during arc welding of aluminum, and the columnar to dendrites transition (CET) was observed with the variation of $\mathrm{G} / \mathrm{R}$ under different welding speed. However, the distribution of solidification parameters was only calculated along a line before, and three-dimensional view has not been given, which increases the simulation complexity but gives a special insight into the welding metallurgy behavior inside the welding liquid pool and contributes to understanding the solidification characteristics deeply and accurately.

In this study, a transient three-dimensional fluid flow model was developed to study the thermal behavior, surface tension driven flow mechanism and solidification characteristics during laser linear welding 304 stainless steel. The thermal behavior including the weld pool profile evolution and rate of temperature change was firstly studied, which was also the basic analysis for the driving force. Then, the flow characteristics were presented and explained by the transient thermal characteristics through the analysis of surface tension driven flow. The effect of different driving force was next studied through dimensional analysis method and comparison of simulated temperature and velocity distribution. The surface tension acting on the top surface of the melt pool, which was considered as the main driving force in laser welding, was then quantitatively studied to comprehend the driven mechanism. Finally, the three-dimensional distribution of the solidification parameters (i.e. GR and G/R) was obtained through the sequential coupling of welding metallurgical model and thermal-fluid model to predict the solidified microstructure. The simulation results and prediction were well validated by the experimental observations.

\section{Mathematical modelling}

\subsection{Governing equations}

In this investigation, a proposed thermal-fluid-metallurgical model was developed to study the heat transfer and fluid flow, and solidification characteristics during laser linear welding of 304 stainless steel. The processing parameters, heat boundary and momentum boundary conditions, driving force acting on the flow were all presented in Fig. 1. The chemical composition of 304ss could be found in reference [13], and not listed here. The thermal physical properties and parameters used in simulation were listed in Table 1 and Table 2, respectively. The effective absorption coefficient was considered to be the function of wavelength and the substrate resistivity [23].To simplify the simulation, some major assumptions had been adopted as follows: the laser heat input was assumed to be a Gaussian distribution; the fluid flow in the molten pool was Newtonian, laminar and incompressible; the mushy zone where the temperature was between the solidus and liquidus was assumed to be a porous medium with isotropic permeability 
Table 1

Thermal physical properties used for the simulation [13].

\begin{tabular}{ll}
\hline Property & $304 \mathrm{ss}$ \\
\hline Liquidus temperature $(\mathrm{K})$ & 1727 \\
Solidus temperature $(\mathrm{K})$ & 1672 \\
Heat of fusion $(\mathrm{kJ} / \mathrm{kg})$ & 272 \\
Specific heat of solid $(\mathrm{J} / \mathrm{kg} \cdot \mathrm{K})$ & 711.28 \\
Specific heat of liquid $(\mathrm{J} / \mathrm{kg} \cdot \mathrm{K})$ & 836.8 \\
Thermal conductivity of solid $(\mathrm{W} / \mathrm{m} \cdot \mathrm{K})$ & 33 \\
Thermal conductivity of liquid $(\mathrm{W} / \mathrm{m} \cdot \mathrm{K})$ & 29 \\
Solid density $\left(\mathrm{kg} / \mathrm{m}^{3}\right)$ & 7450 \\
Liquid density $\left(\mathrm{kg} / \mathrm{m}^{3}\right)$ & 6910 \\
Dynamic viscosity $(\mathrm{kg} / \mathrm{m} \cdot \mathrm{s})$ & $6.67 \times 10^{-3}$ \\
Surface tension $(\mathrm{N} / \mathrm{m})$ & 1.872 \\
Temperature coefficient of surface tension $(\mathrm{N} / \mathrm{m} \cdot \mathrm{K})$ & $-4.3 \times 10^{-4}$
\end{tabular}

Table 2

Parameters used in calculation [15].

\begin{tabular}{ll}
\hline Parameter & Value \\
\hline Power distribution factor & 2 \\
Laser absorption efficiency & 0.26 \\
Ambient temperature & $300 \mathrm{~K}$ \\
Convective heat transfer coefficient at top surface & $100\left(\mathrm{~W} / \mathrm{m}^{2} \mathrm{~K}\right)$ \\
Emissivity & 0.2 \\
Stefan-Boltzmann constant & $5.67 \times 10^{-8}\left(\mathrm{~W} / \mathrm{m}^{2} \mathrm{~K}^{4}\right)$
\end{tabular}

$[25,26]$; the relevant thermal and physical properties of the substrate, such as thermal conductively and specific heat, were temperature-independent.

Based on above assumptions, the governing equations that model the welding process are presented as follows:

The equation of conservation of mass is:

$\frac{\partial \rho}{\partial t}+\nabla \cdot(\rho \mathrm{u})=0$

where $\rho$ is the density of the liquid metal and $u$ is the velocity vector.

The equation of momentum is:

$\rho \frac{\partial \mathbf{u}}{\partial t}+\rho(\mathbf{u} \cdot \nabla) \boldsymbol{u}=\nabla \cdot\left[-p \boldsymbol{I}+\mu(\nabla \boldsymbol{u}+(\nabla \boldsymbol{u}))^{T}-\frac{2}{3} \boldsymbol{u}(\nabla \cdot \boldsymbol{u}) \boldsymbol{I}\right]+K \boldsymbol{u}$

where

$\mathrm{K}=\frac{K_{0}\left(1-f_{l}\right)^{2}}{\left(f_{l}^{3}+M\right)}$

In Eq. (2), $\mu$ and p represent the viscosity and the pressure of the fluid, respectively. $\mathrm{K}$ is the drag coefficient for a porous media model in the mushy zone, $K_{o}$ is a constant parameter representing the mushy zone morphology, $f_{l}$ is the liquid fraction and $\mathrm{M}$ is small positive number used to avoid the division by zero. In this work, $K_{o}$ and $\mathrm{M}$ are taken as $10^{7}$ and $10^{-4}$, respectively. The liquid fraction in this study could be expressed as:

$\mathrm{f}_{l}=\left\{\begin{array}{cl}0, & 0<T<T_{s} \\ \frac{T-T_{s}}{T_{l}-T_{s}}, & T_{s}<T<T_{l} \\ 1, & T>T_{l}\end{array}\right.$

where $T_{S}$ and $T_{s}$ are the solidus and liquidus temperature, respectively.

The equation of energy is:

$\rho C_{p} \frac{\partial T}{\partial t}+\rho C_{p} \boldsymbol{u} \cdot \nabla T=\nabla \cdot(K \nabla T)-\rho \frac{\partial(\Delta H)}{\partial t}-\rho \boldsymbol{u} \nabla(\Delta H)$

where $C_{p}$ is the specific heat, $\mathrm{K}$ is the thermal conductivity, and $\Delta H$ is the latent enthalpy change caused by the phase change in the computational cell, which is given as :
$\Delta H=L f_{l}$

where $\mathrm{L}$ denotes the latent heat of fusion.

\subsection{Boundary conditions}

The heat flux at top surface is described as:

$q_{\text {ener }}=\frac{2 \eta Q}{\pi r_{b}^{2}} \exp \left(-\frac{2 r^{2}}{r_{b}^{2}}\right)-h_{c}\left(T-T_{0}\right)-\sigma_{b} \varepsilon\left(T^{4}-T_{0}^{4}\right)$

The three terms in the right hand of the Eq. (7) represent the laser heat input, heat loss caused by convection and radiation, respectively. In Eq. (7), $\eta$ and $Q$ are the effective absorption efficiency of the stainless steel and laser power adopted in the simulation and experiment. $r$ and $r_{b}$ represent the distance from the grid node to the center of the laser beam and the effective radius of the laser beam, respectively. $h_{c}$ is the convection heat transfer coefficient, $\sigma_{b}$ is the Stefan-Boltzmann constant, $\varepsilon$ is the emissivity and $T_{0}$ is the ambient temperature.

Besides, convection and radiation are applied to the bottom and lateral boundaries of both the solid and fluid domain, viz:

$q_{\text {loss }}=h_{c}\left(T-T_{0}\right)-\sigma_{b} \varepsilon\left(T^{4}-T_{0}^{4}\right)$

At the top surface of the molten pool, the Marangoni effect induced surface shear stress is applied as a boundary condition to the fluid flow as follows:

$\mu \frac{\partial u}{\partial z}=-f_{l} \frac{d \gamma}{d T} \frac{\partial T}{\partial x}$

$\mu \frac{\partial v}{\partial z}=-f_{l} \frac{d \gamma}{d T} \frac{\partial T}{\partial y}$

where $\mathrm{u}$ and vare the velocity vector, and $\gamma$ represents the surface tension.

The model geometry and mesh grids used for the simulation were shown in Fig. 2. A fine unstructured tetrahedral mesh with maximum element size of $80 \mu \mathrm{m}$ was applied in the fluid domain where the phase changes from solid to liquid occurred, while a tetrahedral mesh with a maximum element size of $400 \mu \mathrm{m}$ was specified in the solid domain where only the heat conduction equation was solved. The mesh grids consist of 190,616 domain units, and the discretization equations were calculated with a maximum time step of $0.1 \mathrm{~ms}$. Mesh-independent test had been carried out by discretizing the model using finer meshes, and the comparison between this test and the results discussed in the paper is listed in the follow Table 3. It was demonstrated that the differences of melt pool dimension, the peak values of temperature and velocity under these two mesh grids were so small, and the effect of mesh size on simulation results could be neglected here.

\subsection{Experimental procedure}

304 stainless steel sheets with size of $40 \mathrm{~mm} \times 40 \mathrm{~mm} \times 2 \mathrm{~mm}$ were used as samples, and the laser linear welding experiments were performed on a self-developed laser manufacturing system including Nd: YAG continuous fibre laser, five-axis computerized numerical control (CNC) working system and clamping platform. Before experiments, the impurities, such as the oil, were removed using acetone. The laser welding parameters applied in the experiments were presented in Table 4.

After the experiments, metallographic samples were prepared by sectioning the welded joints along the vertical direction using an electrical discharge wire cutting machine. Then, a HCL:HNO3 solution with a volume ratio of 3:1 was used to etch the samples after the processes of rough grinding, fine grinding, and polishing. The solidification microstructure of the treated specimen was then characterized by TRMC light microscope (OM) and ZEISS EV18 scanning electron microscopy (SEM), respectively. 


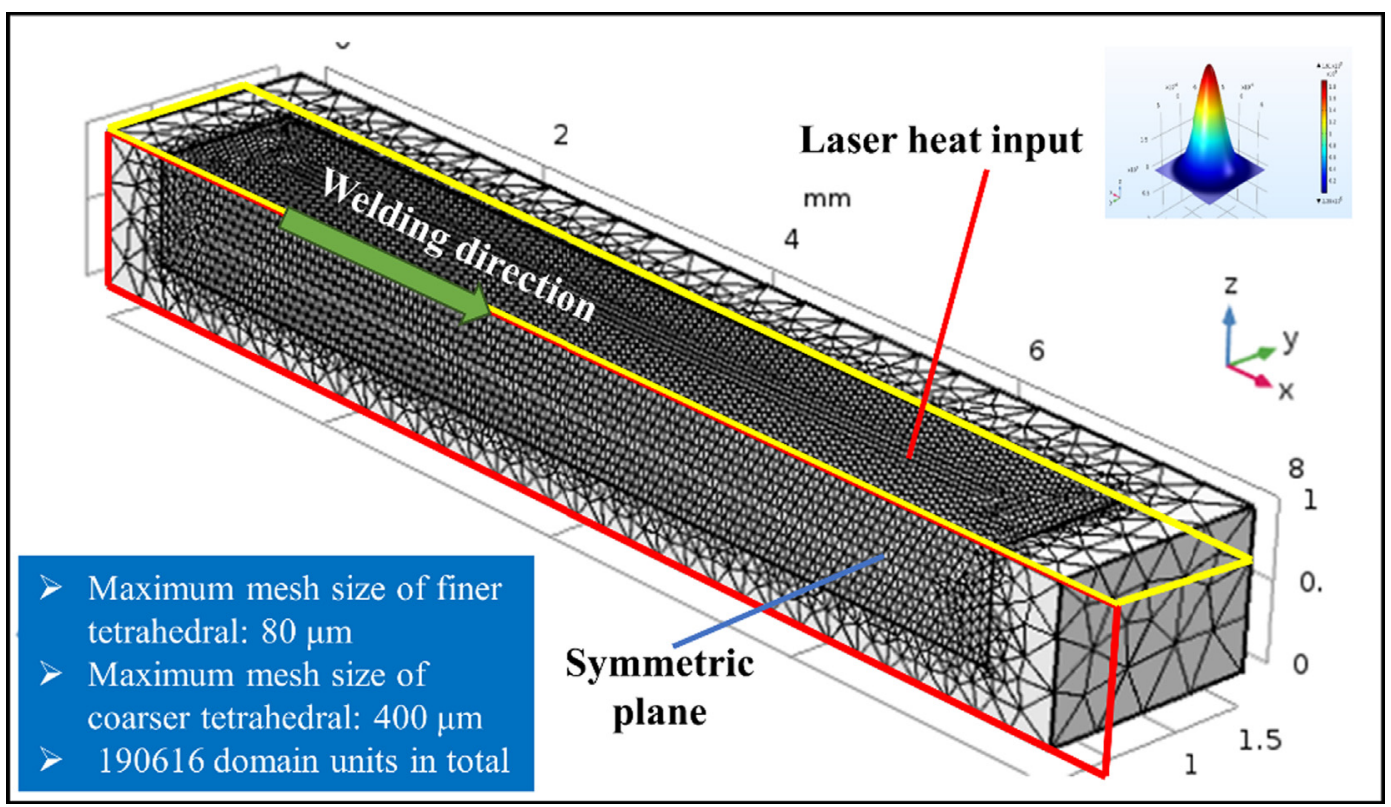

Fig. 2. Model geometry and mesh grids used in simulation.

\section{Results and discussion}

\subsection{Thermal analysis}

Fig. 3 showed the temperature counter of the weld pool at $30 \mathrm{~ms}$ when the welding process reached steady state. It could be observed that the temperature of the front area of the melt pool was higher which was directly under the laser irradiation, and a deeper melt pool was observed at its back where the solidification occurred. The peak temperature during the welding process was around $3000 \mathrm{~K}$ and occurred near the center of the moving laser beam. The melt pool profile along with the isosurfaces of liquid and solid temperature were also illustrated in Fig. 3. The temperature isosurfaces were more concentrated at the front area, which meant that a larger temperature gradient would be observed here. As a result of the melt pool evolution, the weld pool dimension at $\mathrm{x}$ direction was obviously larger than that at $\mathrm{y}$ direction at this moment.

The melt pool profile along with the velocity distribution at $5 \mathrm{~ms}$, $10 \mathrm{~ms}, 20 \mathrm{~ms}$ and $30 \mathrm{~ms}$ were all presented in Fig. 4. To illustrate the melt pool evolution clearly, its position in Cartesian coordinate was moved along the welding direction. As shown in Fig. 4, it took about $30 \mathrm{~ms}$ for the melt pool to fully develop. Besides, the weld pool depth varied with time while the top surface of the weld pool showed a circular distribution at initial stage (from $5 \mathrm{~ms}$ to $20 \mathrm{~ms}$ ). As time passed, it could be obviously observed that the length of the melt pool grew faster in $\mathrm{x}$ direction than that in $\mathrm{y}$ direction (as illustrated by the profile at $30 \mathrm{~ms}$ ). One of the underlying reasons was the change of heat transfer mechanism, which changed from conduction to convection with the increase of Peclet number [23]. The Pe is 7 at $5 \mathrm{~ms}$ and 84 at $30 \mathrm{~ms}$, which meant that the dominant mechanism was conduction and convection, respectively. Under the function of heat conduction, the top surface of the melt pool was approximately circular, and it changed to elliptical when the heat was mainly transported by convection. In
Table 4

Welding parameters used in experiments.

\begin{tabular}{llll}
\hline Laser spot & Shielding gas & Laser power & Welding speed \\
\hline $0.7 \mathrm{~mm}$ & Pure Argon $(15 \mathrm{~L} / \mathrm{min})$ & $900 \mathrm{~W}$ & $20 \mathrm{~mm} / \mathrm{s}$ \\
\hline
\end{tabular}

addition, compared with melt pool evolution in laser spot welding [15], it could also be concluded that melt pool profile was affected by the movement of heart source and its dimension grew faster at the welding direction.

The temperature profile along the welding bead center line under different times during the welding process had been plotted in Fig. 5 . The maximum temperature in the weld pool quickly increased to about $2600 \mathrm{~K}$ within $20 \mathrm{~ms}$ after the welding started, and the position where the peak temperature occurred was exactly under the laser beam. In addition, according to Fig. 5, it could also be observed that the peak temperature almost kept a constant of $2880 \mathrm{~K}$ and the temperature distribution also showed great similarity after $30 \mathrm{~ms}$ until the end of the welding process. It could be reasoned that the welding process reached a steady condition and the heat input equaled to the sum of the absorption and the energy loss mainly caused by the ambient radiation and heat convection with the environment.

The mentioned welding steady condition could also be illustrated by the heating-cooling plot presented in Fig. 6. At initial stage, the heating rate exceeded $1.3 \times 10^{5} \mathrm{~K} / \mathrm{s}$ and quickly dropped to $0.9 \times 10^{5} \mathrm{~K} / \mathrm{s}$ when the welding process reached the steady condition. The position where the peak heating rate occurred changed with the movement of laser heat source and the peak value almost kept constant at different welding times. It should be noted that the peak cooling rate was far lower than the peak heating rate, and always appeared at the rear of the melt pool. There were two underlying reasons that could account for this phenomenon. Solidification occurred behind the melt pool and near the laser beam center, hence, it was inevitably affected by the laser heat

Table 3

Comparison of the simulation results under different meshes.

\begin{tabular}{|c|c|c|c|c|c|}
\hline Maximum mesh size of finer tetrahedral (mm) & Domains in total & Maximum temperature (K) & Maximum velocity (m/s) & Weld width (mm) & Weld depth (mm) \\
\hline 0.05 & 748,918 & 2960 & 1.05 & 1.70 & 0.35 \\
\hline 0.08 & 190,616 & 2950 & 1.01 & 1.65 & 0.34 \\
\hline
\end{tabular}




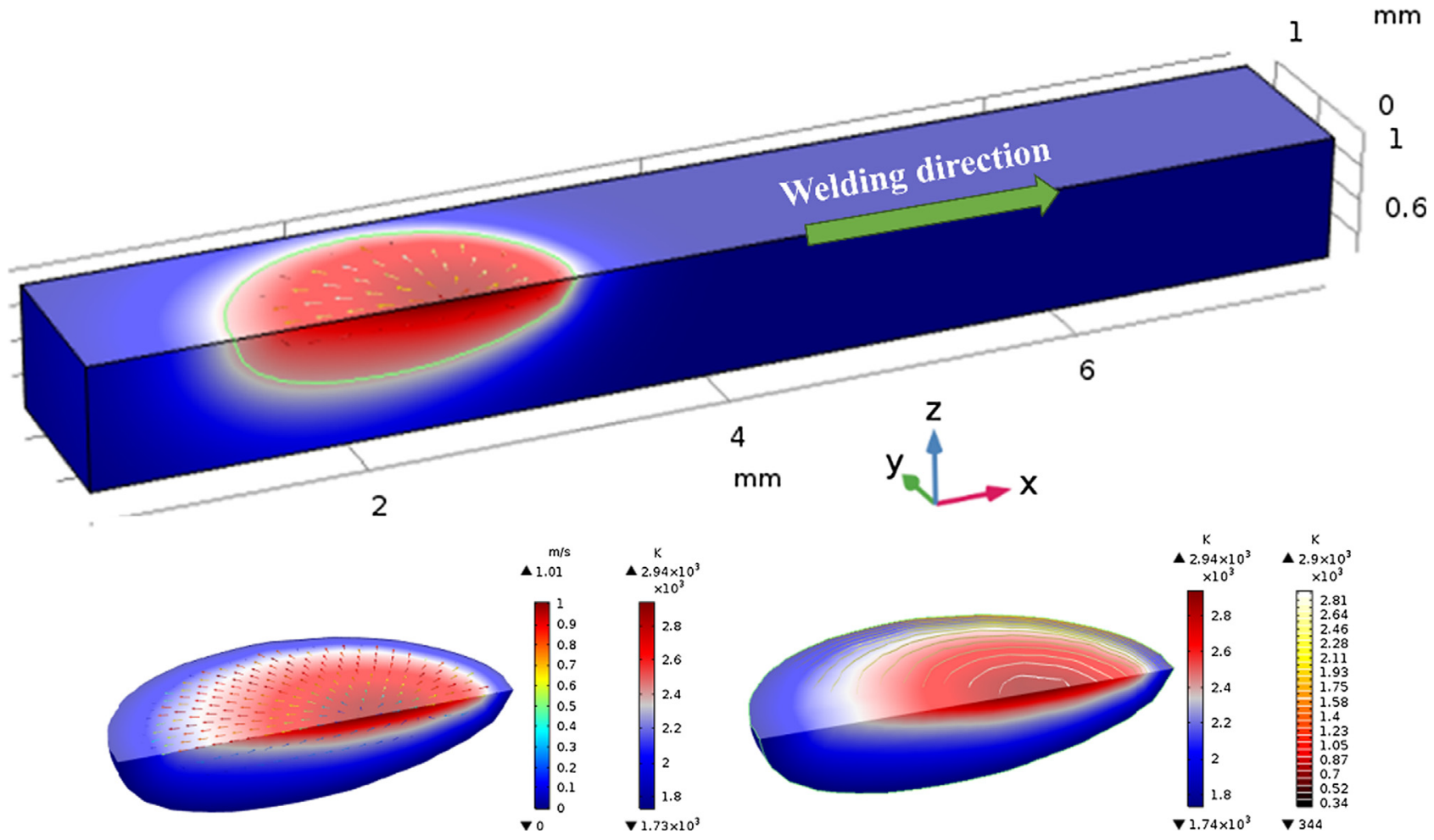

Fig. 3. Melt pool profile and temperature field with isotherms.

input and the peak cooling rate was relatively lower. In addition, it could also be explained by the latent heat during the quick solidification of the liquid metal after the laser swept.

\subsection{Fluid flow}

A comparison of the melt pool profile obtained from the numerical simulation and experimental result was presented in Fig. 7. As depicted in figure, the melt pool dimension was well predicted within a 5\% margin. This reasonable agreement validated the efficiency of the numerical model, which would be used in the transient thermal analysis to study the solidification characteristics.

The liquid fraction at the central xz plane was presented by the color contour in Fig. 8, the value 0 and 1 represented the solid and liquid phase, respectively. The streamlines along with the temperature gradient vectors were also shown, and represented by the blue lines and white arrows, respectively. Besides, two separate circulations were observed at the front and the back of the melt pool, and the temperature gradient vectors were all vertical to the liquidus and solidus lines. However, the circulation at the frontal part was obviously smaller, compared with that at back. Because the liquid flow at front was restricted by the mushy zone where the viscosity was enormous compared with that at back, hence, a much smaller circulation was thus formed. Meanwhile, the rear circulation developed much bigger since the melt pool was well-expanded backwards.

The rate of temperature change in melt pool could also be studied in a 3D vision. As shown in Fig. 9(A), the rate was represented by color contour, and there were obviously two different heating and cooling part in the front and the back of the weld pool, respectively. The front part presented a positive rate of temperature change, while value at back was negative. In addition, the maximum heating rate was $50 \%$ higher than that of cooling rate. Compared with Fig. 5, it could also be

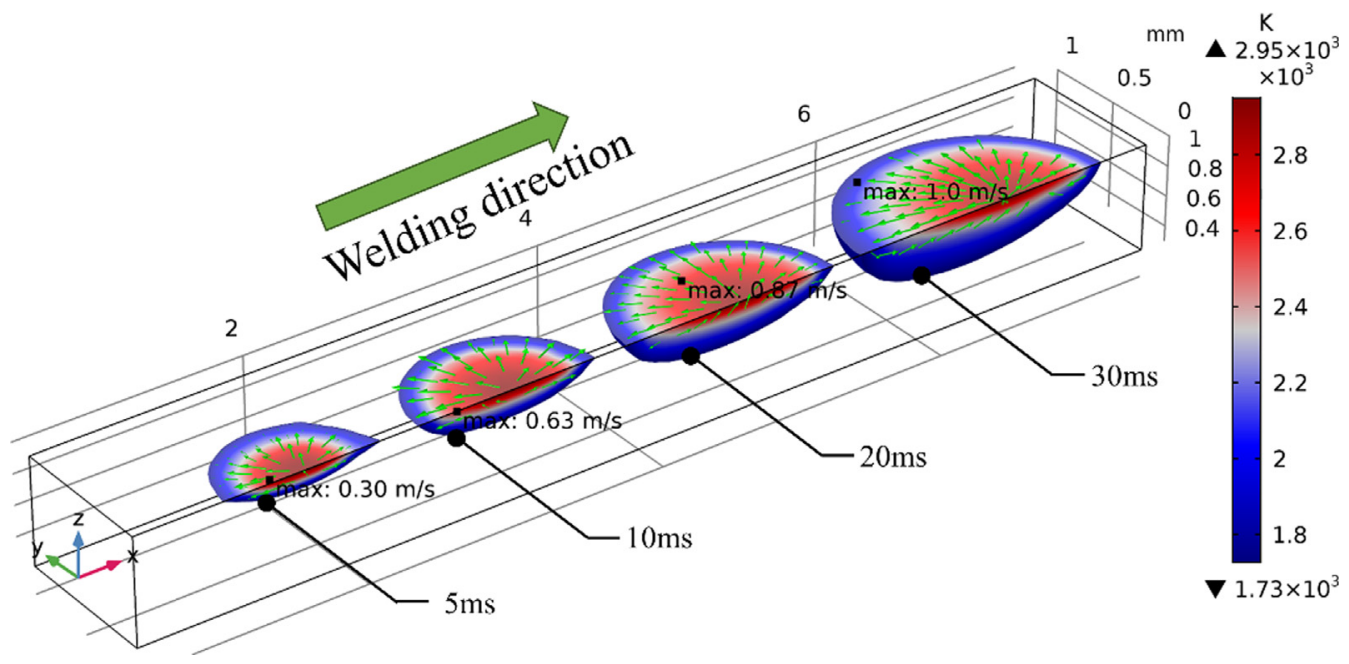

Fig. 4. Melt pool profile evolution from $5 \mathrm{~ms}$ to $10 \mathrm{~ms}, 20 \mathrm{~ms}$, and $30 \mathrm{~ms}$. 


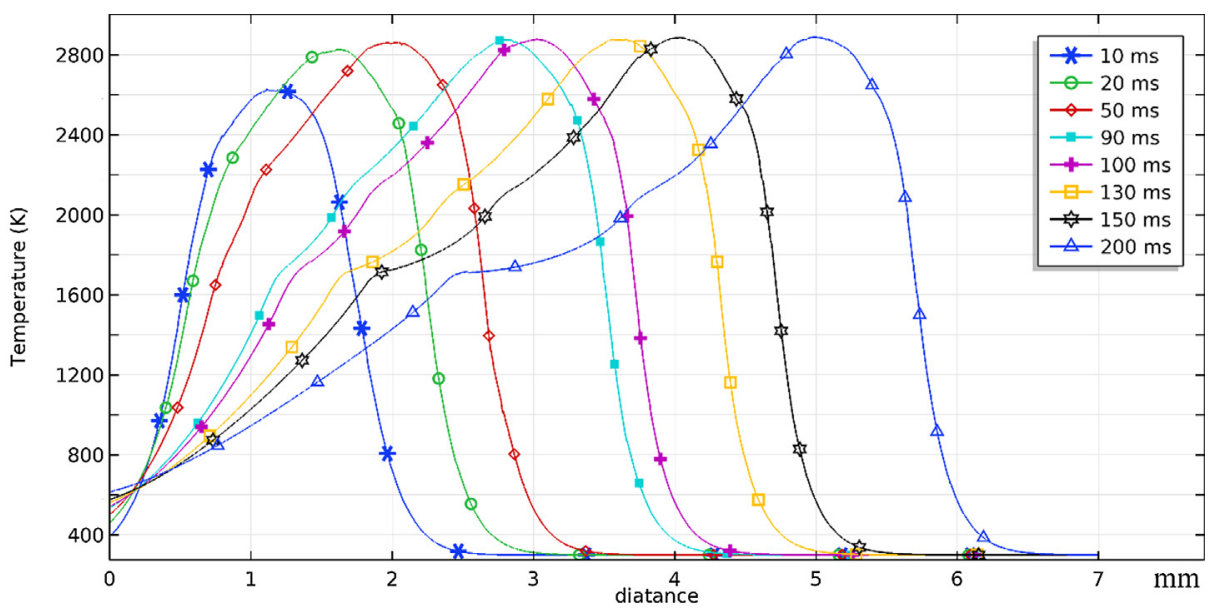

Fig. 5. Temperature profile on the welding central line $(\mathrm{z}=1 \mathrm{~mm})$.

concluded that the front area was still in the heating stage because the temperature in this part was lower than the peak temperature. As a result, a positive rate of temperature change could be predicted at the front part; on the contrast, a negative rate was observed at back.

The 3D distribution of the temperature gradient inside the weld pool was depicted in Fig. 9 (B), and it decreased from center to the periphery. As illustrated in Fig. 9(C), the surface tension was smaller in the central area due to the Marangoni effect, and decreased from center to the periphery. The calculated velocity distribution was presented in Fig. 9(D), the magnitude of the velocity was characterized by the color contour and the vector arrows represented both the direction and the value of the velocity field. A much stronger fluid flow was prompted by higher driving force, thus the velocity near the periphery was larger than that in the center, which was consistent with the discussion above. Based on the surface tension and temperature coefficient of surface tension listed in Table.1(1.872 N/m and $-4.3 \times 10-4 \mathrm{~N} / \mathrm{m} / \mathrm{K}$, respectively), which were related to the calculation of surface tension, the driving force distribution was quantitatively computed next to study the influence of thermal behavior on fluid flow.

\subsection{Driving forces}

The driving forces for the fluid flow inside the melt pool were greatly affected by the thermal behavior discussed above, and its driving mechanism would be investigated in this part. Several non-dimensional numbers had been used to study the effect of processing parameters and material properties on the heat transfer and fluid flow.
The Grashof number and Marangoni number were vital to comprehend the driving mechanism of the surface tension flow, which was associated with the thermal behavior. In summary, the significance, mathematical expression and adopted value in this study were all listed in Table.6. Where $\Delta$ Tis the difference between the peak temperature and solidus temperature, and $\mathrm{L}_{\mathrm{b}}$ was the characteristic length for the buoyance, which was taken as one eight of the weld width in this study. According to the computed results, the relative importance of surface tension to buoyance could be expressed as:

Ratio $=\frac{\text { surface tension }}{\text { bouyance }}=\frac{M_{a}}{G_{r}}$

The ratio was on the order of $10^{5}$, hence, it could be concluded that the fluid was mainly driven by the surface tension.

To comprehend the effect of driving force, temperature and velocity distribution under different driving forces were calculated. As illustrated in Fig. 10, the melt pool dimension only considering heat conduction was obviously much larger than any other situations, followed by the dimension only considering buoyance. The Peclet number [13] under buoyance was on the order of $10^{-1}$, which meant that heat transfer was dominated by conduction. As a result, the melt pool was larger and peak temperature was higher. Under the effect of strong outward Marangoni convection, the Peclet number was computed to be over 10, and convection became the dominant heat transfer mechanism. Consequently, the temperature distribution was more uniform, the peak temperature was lower and the melt pool was obviously shallow when surface tension was considered.

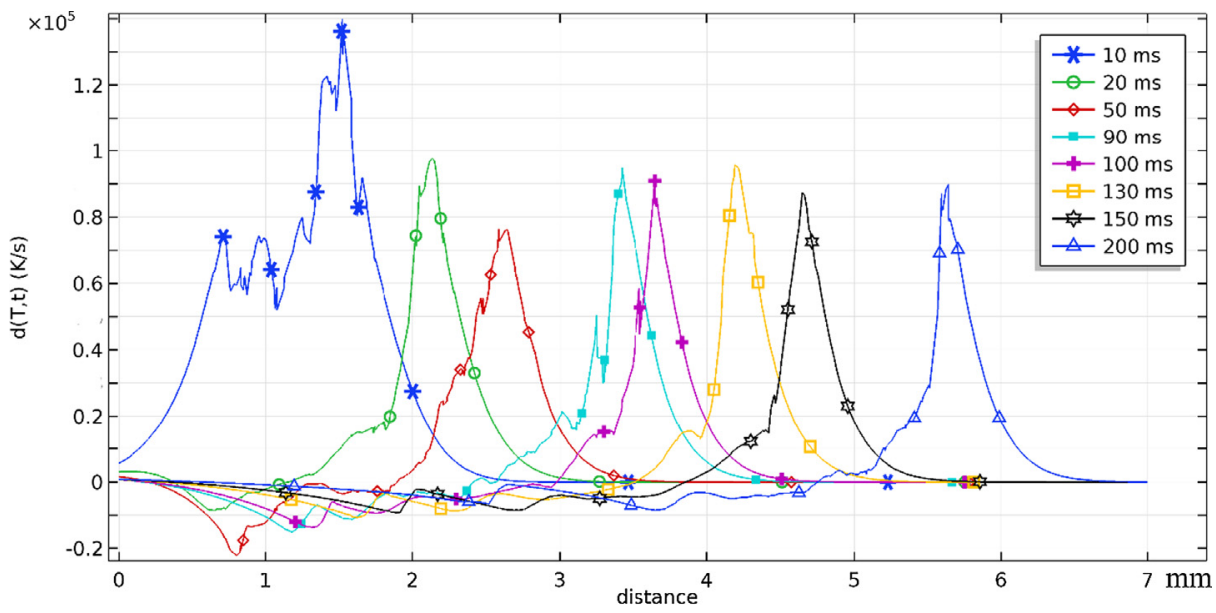

Fig. 6. Rate of temperature change on the welding central line $(\mathrm{z}=1 \mathrm{~mm})$. 


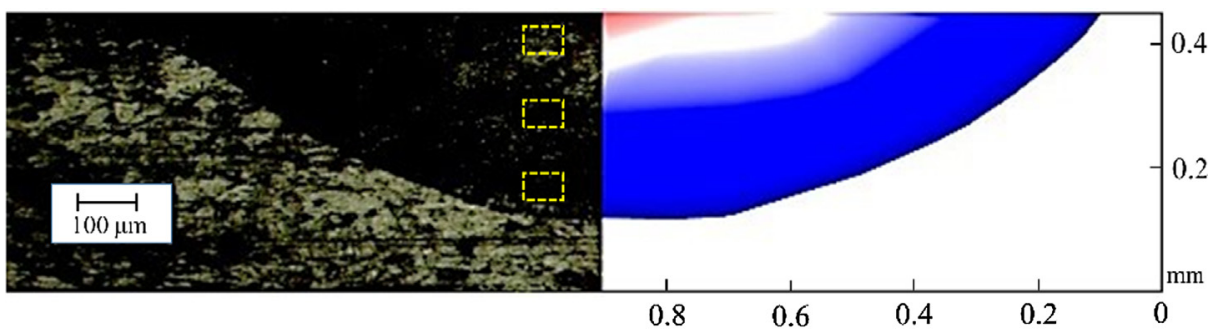

Fig. 7. Comparison of simulated and experimentally observed weld pool dimension.

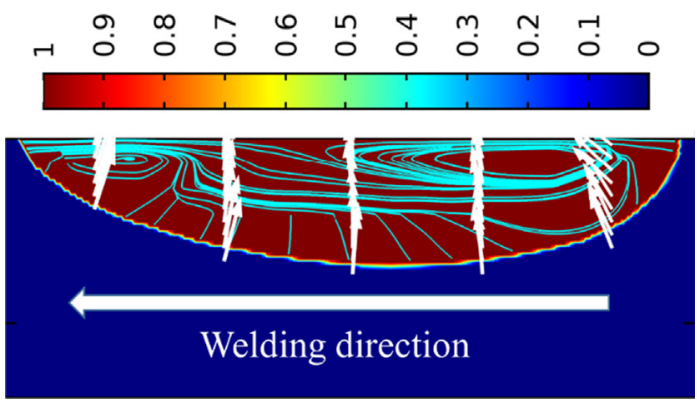

Fig. 8. The melt pool profile at the central xz plane along with liquid fraction contour.

As mentioned above, the surface tension associated with Marangoni convection played an important role in the driving mechanism of fluid flow. The surface section was found to be the function of temperature and concentration of surface active elements (e.g. oxygen and sulfer) $[21,28]$. In this study, the role of surface active elements was ignored because the welding was performed under the protecting gas of argon and the concentration of active elements could be assumed unchanged in the same material (304ss). Consequently, the surface tension for Fe$\mathrm{Ni}$ binary system in this paper could be expressed as:

$\gamma(T)=\gamma_{m}-A_{\gamma}\left(T-T_{l}\right)-R_{u} T \Gamma_{s} \ln \left(1+K \alpha_{s}\right)$

$\mathrm{K}=k_{l} \exp \left(-\Delta H^{0} / R_{u} T\right)$

where $\gamma$ is the surface tension and $\gamma_{m}$ is the surface tension of pure metal at the melting temperature. $A_{\gamma}$ and $R_{u}$ represent the surface tension temperature coefficient and the universal gas constant, respectively. $\Gamma_{s}$ is the surface excess at saturation, $k_{l}$ is the a constant corresponding to the segregation entropy, $\Delta H^{0}$ is the standard heat of adsorption and $\alpha_{s}$ is the activity of the sulfer which could be approximated by the sulfer concentration (weight $\%, 0.03 \%$ in the simulation). The related parameters used to calculate the surface tension were listed in Table 5.

The surface tension distribution at the welding center line under different times was presented in Fig. 11. It increased from the center of the melt pool to the periphery due to the negative surface tension temperature coefficient, which indicated that the surface tension decreased with the increase of temperature. As the melt pool developed, the maximum temperature increased to about $2880 \mathrm{~K}$ and kept a constant when the welding process reached the steady condition. Accordingly, the minimum surface tension continued to decrease, and eventually reached $1.28 \times 10^{-4} \mathrm{~N} / \mathrm{m}$.

The surface shear stress caused by surface tension that drive the Marangoni convection was determined by the temperature term $\frac{d \gamma}{d T} \frac{\partial T}{\partial s}$ in this study (the effect of active elements term $\frac{\partial \gamma}{\partial C} \frac{d C_{S}}{d s}$ was not considered). Fig. 12 showed the distribution of $\frac{d \gamma}{d T} \frac{d T}{d x}$ along the welding center line at times of 10, 20, 30, 40 and $50 \mathrm{~ms}$. As illustrated in Fig. 5, the temperature distribution experienced abrupt change in the area near the fusion line, which resulted in large temperature derivative. Consequently, the peak value of surface tension shear stress was observed at the liquid/solid boundaries. The positive and negative value meant that the acting direction of the surface shear stress was along the $\mathrm{x}$-axis and the opposite direction, respectively. It was qualitatively explained in Figs. 11 and 12 that the driving force was smaller at the center of the melt pool, as a result, the convection was relatively weak and velocity was smaller compared with that at periphery (Fig. 9 (D)). Besides, there was obvious difference of the surface shear stress between the front and back, which was about $2500 \mathrm{~N} / \mathrm{m}^{2}$ at front and $1000 \mathrm{~N} / \mathrm{m}^{2}$ at back. The solidified welding bead experienced the melting and solidification process, hence, its temperature derivative was relatively smaller

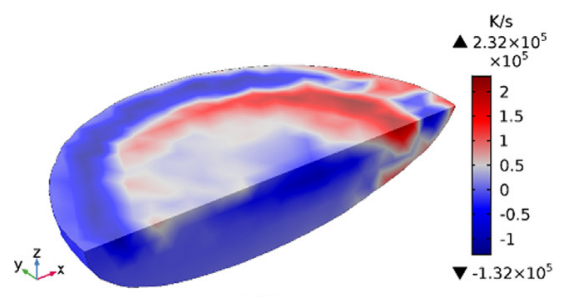

(A)

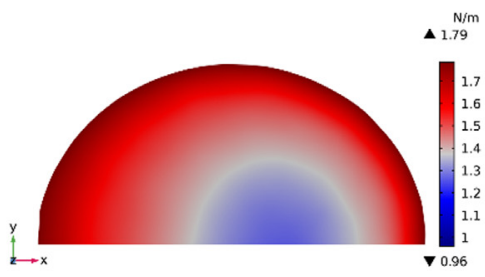

(C)

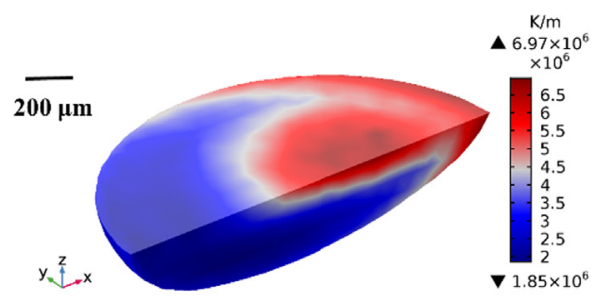

(B)

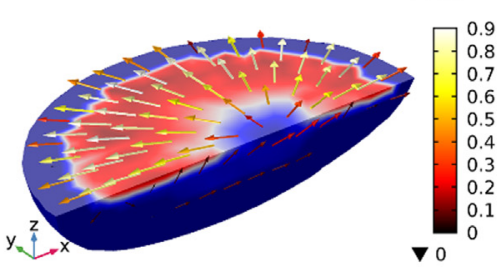

(D)

Fig. 9. Temperature related surface tension driven flow (A) rate of temperature change; (B) temperature gradient distribution; (C) surface tension distribution on the top surface of the melt pool; (D) 3D visualization of the melt pool along with velocity field distribution. 


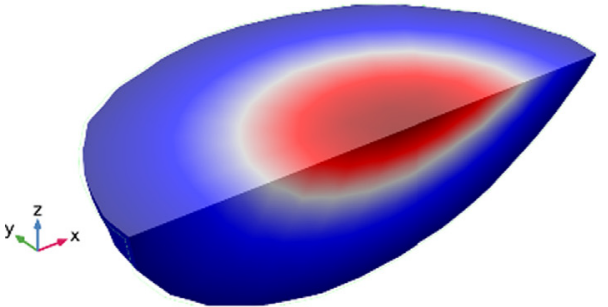

(A)

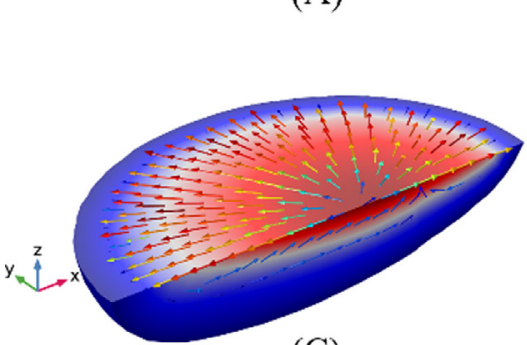

(C)
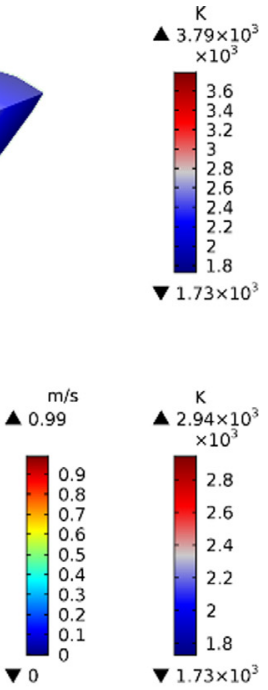

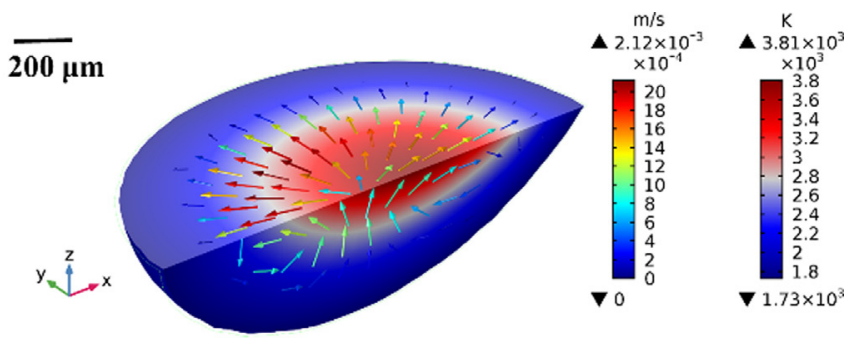

(B)

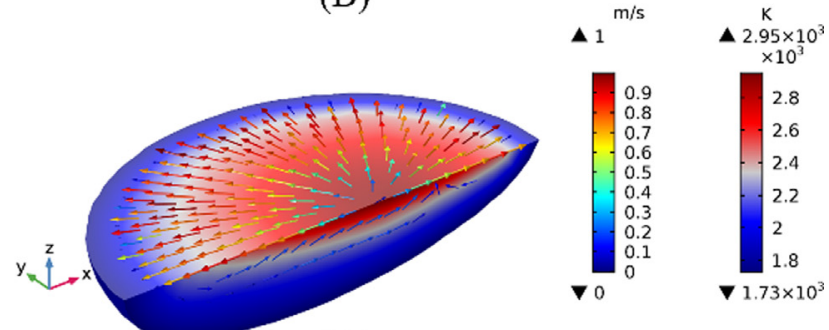

(D)

Fig. 10. Weld pool dimension, temperature and velocity field under different driving forces; (A) Heat conduction; (B) Buoyance; (C) Surface tension; (D) Buoyance and surface tension.

Table 5

Parameters for surface tension calculation [27].

\begin{tabular}{lllll}
\hline$\gamma_{m}[\mathrm{~N} / \mathrm{m}]$ & $A_{\gamma}[\mathrm{N} / \mathrm{mK}]$ & $\Gamma_{s}\left[\mathrm{kmol} / \mathrm{m}^{2}\right]$ & $k_{l}$ & $\Delta H^{0}[\mathrm{~kJ} / \mathrm{kmol}]$ \\
\hline 1.943 & $4.3 \times 10^{-4}$ & $1.3 \times 10^{-8}$ & 0.00318 & $-1.66 \times 10^{8}$ \\
\hline
\end{tabular}

Table 6

Non-dimensional numbers used to study the driving force in LBW.

\begin{tabular}{llll}
\hline ND numbers & Significance & Expression & Value \\
\hline Grashof number (Gr) & $\begin{array}{l}\text { The ration of buoyance force } \\
\text { to viscous force }\end{array}$ & $g \beta L_{b}^{3} \Delta T \rho^{2} / \mu^{2}$ & 0.459 \\
$\begin{array}{ll}\text { Marangoni number } \\
\text { (Ma) }\end{array}$ & $\begin{array}{l}\text { The ratio of surface tension } \\
\text { to viscous force }\end{array}$ & $\rho L_{R} \Delta T|\partial \gamma / \partial T| / \mu^{2}$ & $4.48 \mathrm{e} 4$ \\
& & &
\end{tabular}

compared with that at front. Accordingly, the surface shear stress was found to be larger near the front boundary and smaller at rear boundary.

The surface shear stress distribution at the top surface of the melt pool under times of $10 \mathrm{~ms}, 20 \mathrm{~ms}, 30 \mathrm{~ms}$ and $40 \mathrm{~ms}$ were illustrated in
Fig. 13. The magnitude of surface shear stress and velocity field were presented by the color map and green arrows, respectively. As shown in Fig. 13, a centrally outward stress distribution was found and it pushed fluid towards periphery. As the melt pool developed, the maximum shear stress reached $2.5 \times 10^{3} \mathrm{~N} / \mathrm{m}^{2}$. In addition, the difference of shear stress between the center and rear side boundary continued to decrease because temperature derivative at rear part kept decreasing until the melt pool reached steady condition.

\subsection{Solidification characteristics}

The morphology and the scale of the solidification microstructure of the melt pool were greatly influenced by the temperature gradient $G$ and the solidification growth rate $\mathrm{R}$, and their combined parameters GR and G/R [29]. The solidification growth rate, $R$, meant the solidification velocity of the solidification front. Based on transient thermal analysis, temperature gradient $\mathrm{G}$ and solidification growth rate $\mathrm{R}$ could be expressed as $[23,24]$ :

$\mathrm{G}=\|\nabla T\|$

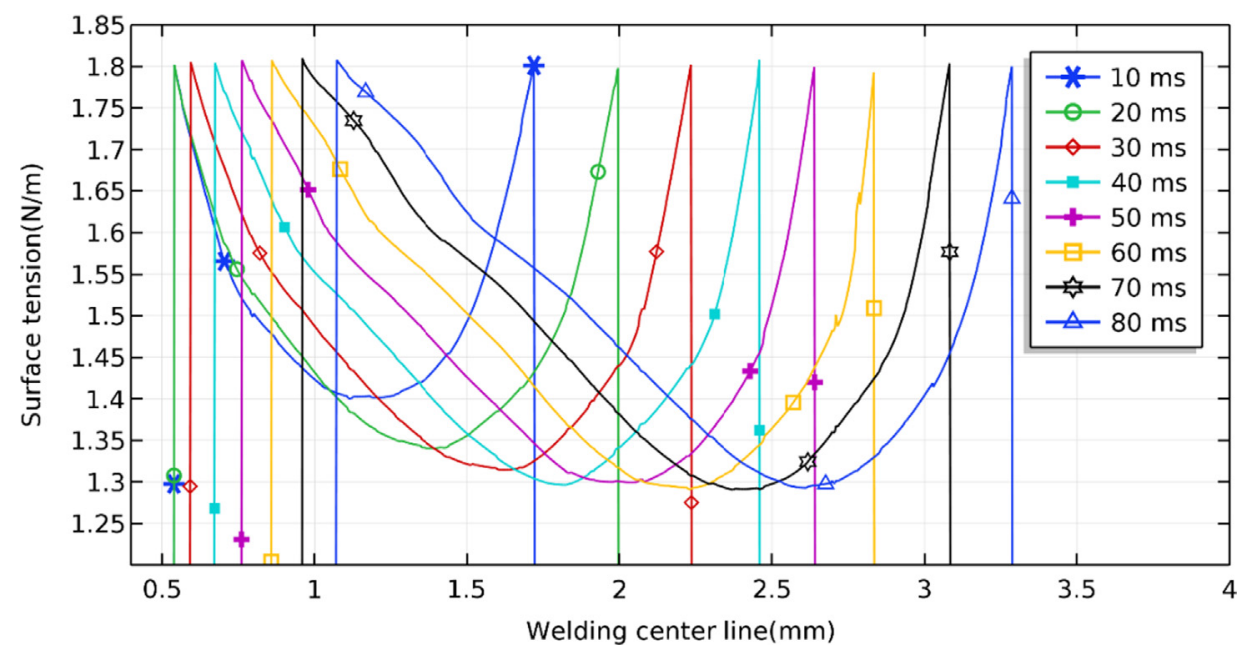

Fig. 11. Surface tension distribution along the welding center line at different times $(\mathrm{z}=1 \mathrm{~mm})$. 


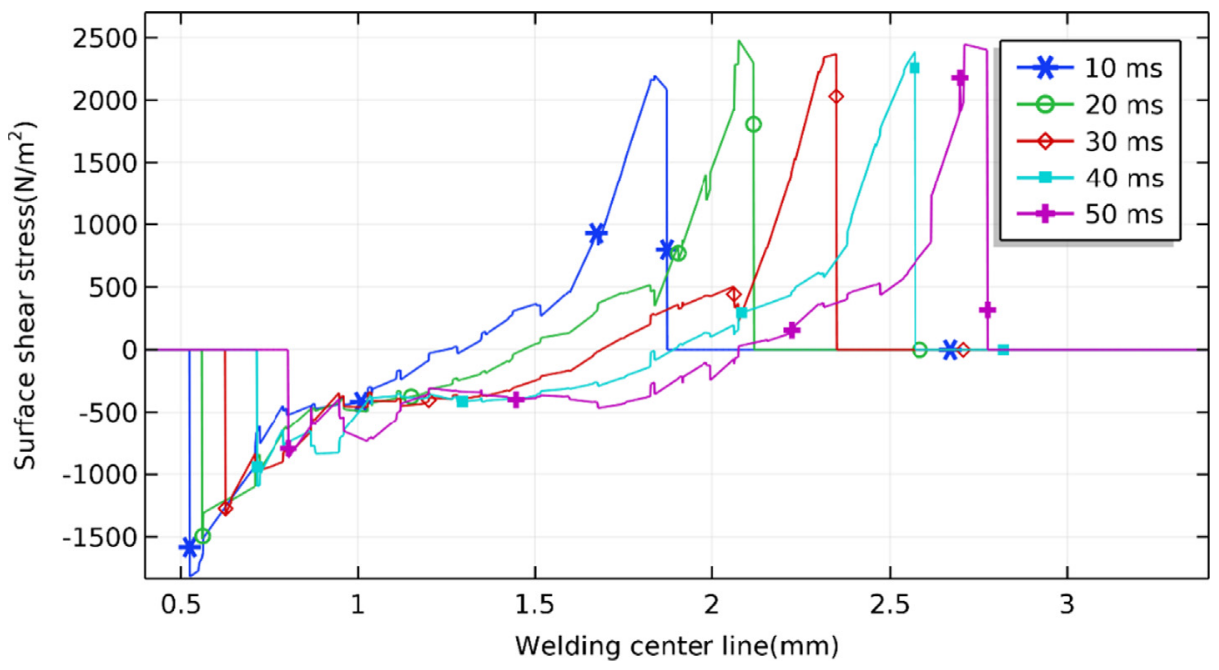

Fig. 12. Surface shear stress distribution along the welding center line at different times.

$\mathrm{R}=\mathrm{u} \frac{(\partial T / \partial x)}{G}$

in which $\mathrm{u}$ is the welding speed ( $20 \mathrm{~mm} / \mathrm{s}$ in this study). $\mathrm{G}$ and $\mathrm{R}$ could be directly calculated from the numerical model, and then GR and G/R could be obtained.

The morphology of the solidified structure was sensitive to the ratio of the temperature gradient and the solidification growth rate, which could be expressed as G/R. Generally, the morphology changed from the equiaxed dendrites to columnar dendrites to cell dendrites with the increase of G/R. Additionally, the final scale of the solidification structure was highly dependent on the cooling rate, which could be expressed as GR. Generally, higher GR resulted in finer grains. Grain refinement was vital to the improvement of the mechanical properties of the joint, thus it was necessary to study the solidification behavior through the suquential coupling of welding metalurgical model with thermal-fluid model. $\mathrm{G}$ and $\mathrm{R}$ could be directly calculated from the welding metallurgical model, and then the morphology parameter $\mathrm{G} / \mathrm{R}$ and the cooling rate could be obtained.
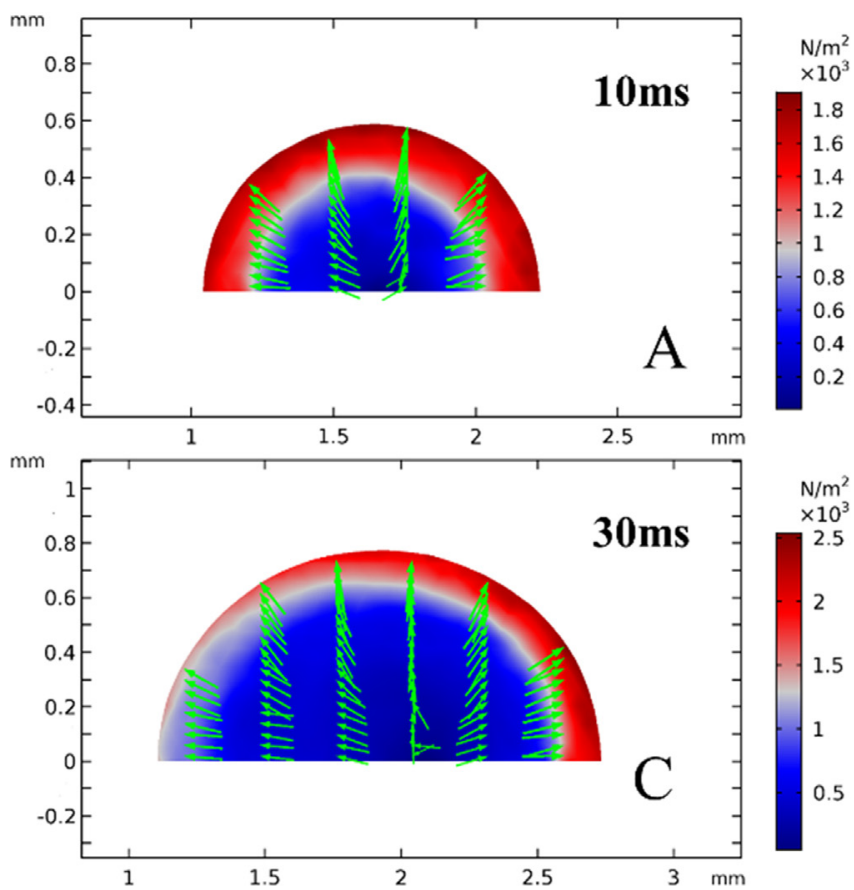

Fig. 13. Surface shear stress distribution at the top surface at different times; (A) $10 \mathrm{~ms}$; (B) $20 \mathrm{~ms}$; (C) $30 \mathrm{~ms}$; (D) $40 \mathrm{~ms}$.
The temperature gradient and solidification growth rate were plotted in Fig. 14(A) and Fig. 14(B), respectively. Maximum temperature gradient was observed at the center of the molten pool, and $\mathrm{G}$ increased over threefold from $3000 \mathrm{~K} / \mathrm{mm}$ in the bottom to $8000 \mathrm{~K} / \mathrm{mm}$ in the center in the cross-section. Maximum solidification growth rate was observed at the top surface of the melt pool, and it changed over ninefold from $2 \mathrm{~mm} / \mathrm{s}$ at the bottom to $19 \mathrm{~mm} / \mathrm{s}$ at the surface. Therefore, it could be basically concluded that solidification growth rate had a greater impact on the solidification characteristics. Cooling rate GR and morphology parameter $\mathrm{G} / \mathrm{R}$ were also depicted in Fig. 14(C) and Fig. 14(D), respectively. As illustrated in the figures, higher GR and lower G/R were observed at the top surface of the weld pool, and lower GR, higher G/R were noticed at the bottom. Consequently, it could be reasonably inferred that the equiaxed dendrites and finer microstructure were prone to occur at the top region of the melt pool, while the coarser solidified structure may be observed at the lower region according to the solidification mechanisms.

The solidified microstructure obtained by SEM at different sections

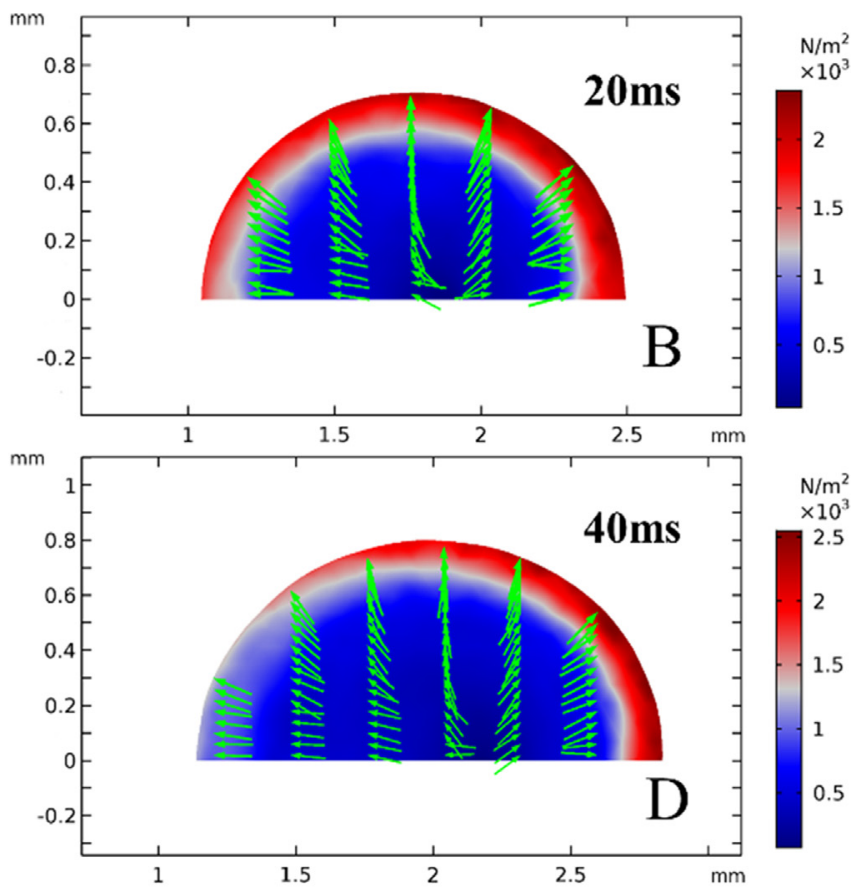




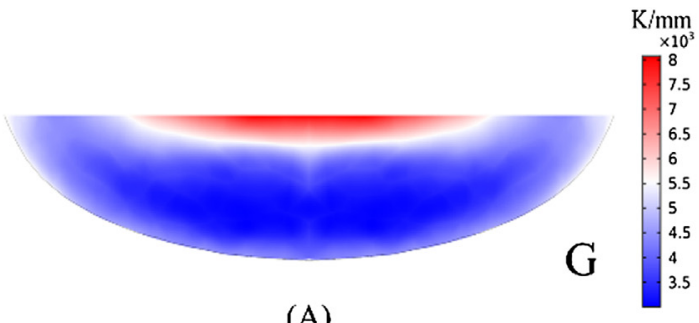

(A)

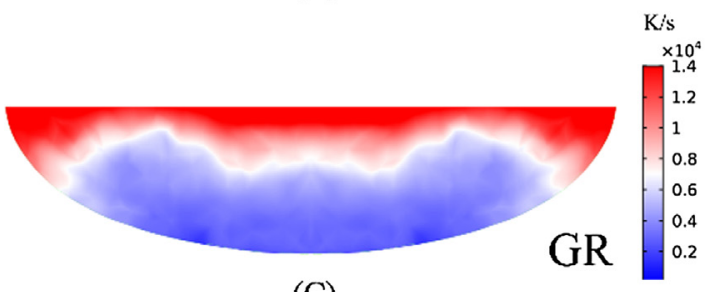

(C)

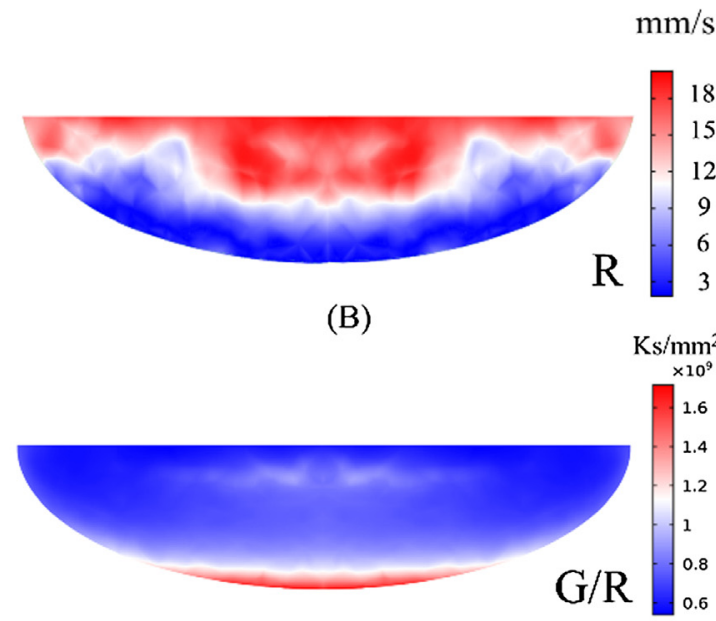

(D)

Fig. 14. Contour of: (A) temperature gradient G; (B) solidification growth rate R; (C) cooling rate GR; (D) morphology parameter G/R.

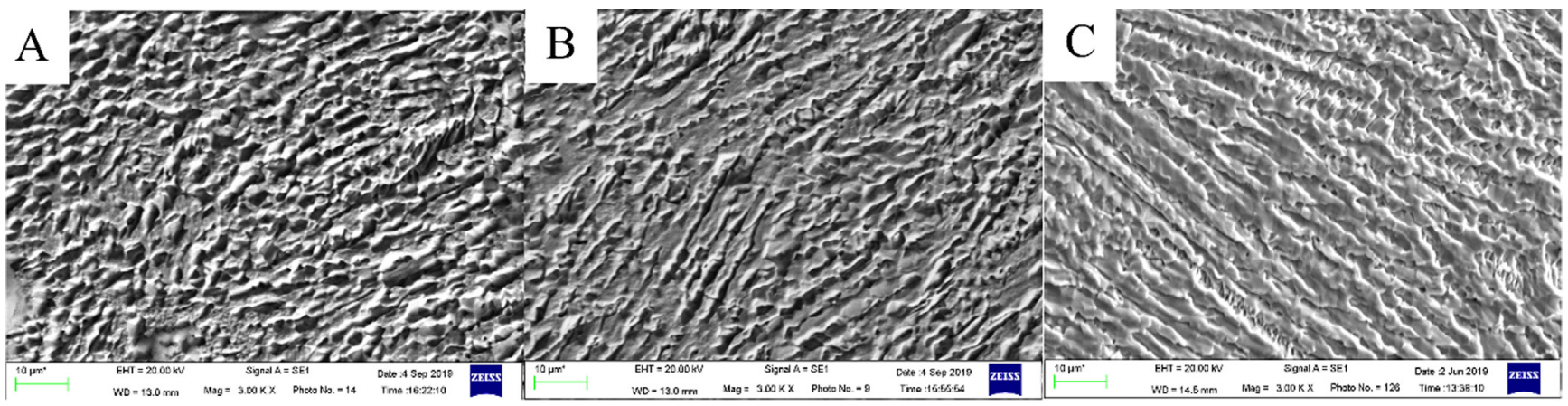

Fig. 15. Solidified microstructure at different sections of the melt pool; (A) top area; (B): middle area; (C) bottom area.

of the melt pool was illustrated in Fig. 15, and the observation locations were marked by the yellow boxes shown in Fig. 7. It was obviously observed that the equiaxed dendrites, the fine columnar dendrites and the coarse columnar dendrites occurred at the top, middle and bottom section of the melt pool, respectively. In conclusion, the experimentally observed result agreed well with the morphology predicted by the simulation.

The improved numerical model presented in this simulation was used to study the thermal behavior, surface tension driven flow and welding metallurgy characteristics. However, both the surface tension and solidification process were influenced by the alloy elements transport. The investigation of solute concentration distribution during welding process should be carried out in future to understand the driving mechanism and metallurgical behavior more deeply and accurately. Other complex factors such as free surface evolution, keyhole dynamics and non-equilibrium solidification due to the large cooling rate also played an important role in the thermal-fluid-metallurgical behavior during laser welding process, and provided great challenges for further studies. Additionally, this analysis of surface tension driven flow and solidification behavior could also be expanded to dissimilar material system. However, the differences of thermal physical parameters, such as the thermal conductivity and dynamic viscosity, make it difficult for the development of numerical model consisting of dissimilar materials $[30,31]$, which is also necessary to be investigated in the future.

\section{Conclusion}

In this study, the thermal behavior, driving force, surface tension driven flow and metallurgical solidification characteristics were investigated utilizing a proposed 3D numerical model. Some basic results could be concluded as follows.

(1) The temperature gradient at the front of the melt pool was larger than that at rear section. It took about $30 \mathrm{~ms}$ for the melt pool to reach the steady state for the influence of latent heat and the movement of laser beam.

(2) The temperature gradient decreased from the center to the periphery of the melt pool. As a result, the driving force and velocity of the fluid flow were all smaller in the central area.

(3) Both the surface tension and surface shear stress increased from the center to the periphery of the melt pool. Centrally outward fluid flow was mainly driven by surface tension, and the maximum surface shear stress may reach $2500 \mathrm{~N} / \mathrm{m}^{2}$.

(4) Since the G/R was bigger at the bottom and GR was larger at top section, the microstructure morphology changed from equiaxed dendrites to fine columnar dendrites to coarse columnar dendrites, and grain size increased from the top to the bottom section of the melt pool.

\section{Acknowledgements}

The authors were grateful for the support from the National Natural Science Foundation of China under grant numbers 11272316, 11272317,11672304 , and 11502269 . This work was also supported by the plan of Beijing Municipal Commission of Science and Technology (Z181100003818015). Besides, the authors thank for the instrument developing project of the Chinese Academy of Sciences (No. yz201636). 


\section{References}

[1] S. Chakraborty, S. Mukherjee, R. Galun, Y. Estrin, I. Manna, Transport phenomena in conduction mode laser beam welding of Fe-Al dissimilar couple with Ta diffusion barrier, Int. J. Heat Mass Transf. 53 (23-24) (2010) 5274-5282.

[2] J.W. Liu, Z.H. Rao, S.M. Liao, H.L. Tsaib, Numerical investigation of weld poo behaviors and ripple formation for a moving GTA welding under pulsed currents, Int. J. Heat Mass Transf. 91 (2015) 990-1000.

[3] W.H. Kim, S.J. Na, Heat and fluid flow in pulsed current GTA weld pool, Int. J. Heat Mass Transf. 41 (21) (1998) 3213-3227.

[4] G. Yu, X.L. He, S.X. Li, Laser Manufacturing and Its Application, National Defense Industry Press, Beijing, 2017.

[5] Dae-Won Cho, Woo-Hyun Song, Min-Hyun Cho, Suck-Joo Na, Analysis of submerged arc welding process by three-dimensional computational fluid dynamics simulations, J. Mater. Process. Tech. 213 (12) (2013) 2278-2291.

[6] F. Lu, X. Tang, H. Yu, S. Yao, Numerical simulation on interaction between TIG welding arc and weld pool, Comput. Mater. Sci. 35 (4) (2006) 458-465.

[7] A. Traidia, F. Roger, Numerical and experimental study of arc and weld pool behavior for pulsed current GTA welding, Int. J. Heat Mass Transf. 54 (9-10) (2011) 2163-2179.

[8] Dae-Won Cho, Suck-Joo Na, Molten pool behaviors for second pass V-groove GMAW, Int. J. Heat Mass Transf. 88 (2015) 945-956.

[9] Zhengtao Gan, Yanping Lian, Stephen E. Lin, Kevontrez K. Jones, Wing Kam Liu, Gregory J. Wagner, Benchmark study of thermal behavior, surface topography, and dendritic microstructure in selective laser melting of inconel 625, Integr. Mater. Manuf. Innov. 8 (2) (2019) 178-193, https://doi.org/10.1007/s40192-01900130-x.

[10] P. Bidare, I. Bitharas, R.M. Ward, M.M. Attallah, A.J. Moore, Fluid and particle dynamics in laser powder bed fusion, Acta Mater. 142 (2018) 107-120.

[11] N. Chakraborty, The effects of turbulence on molten pool transport during melting and solidification processes in continuous conduction mode laser welding of copper nickel dissimilar couple, Appl. Therm. Eng. 9 (2009) 3618-3631.

[12] H.L. Wei, J.W. Elmer, T. DebRoy, Crystal growth during keyhole mode laser welding, Acta Mater. 133 (2017) 10-20.

[13] Z.Y. Li, G. Yu, X.L. He, Study of thermal behavior and solidification characteristics during laser welding of dissimilar metals, Results Phys. 12 (2019) 1062-1072.

[14] X.Y. Chen, G. Yu, X.L. He, S.X. Li, H.B. Miao, Effect of droplet impact on molten pool dynamics in hybrid laser-MIG welding of aluminum alloy, Int. J. Adv. Manuf. Technol. 96 (2018) 209-222.

[15] Y.W. Hu, X.L. He, G. Yu, S.S. Zhao, Capillary convection in pulsed butt welding of miscible dissimilar couple, J. Mech. Sci. Technol. 231 (13) (2016) 2429-2440.

[16] P. Schempp, C.E. Cross, A. Pittner, M. Rethmeier, Solidification of GTA aluminum weld metal: Part 2-Thermal conditions and model for columnar-to-equiaxed transition, Weld. J. 93 (2014) 69S-77S.

[17] X. Meng, G. Qin, Y. Su, B. Fu, Y. Ji, Numerical simulation of large spot laser-MIG arc brazing-fusion welding of $\mathrm{Al}$ alloy to galvanized steel, J. Mater. Process. Technol. 222 (2015) 307-314.

[18] T. DebRoy, H.L. Wei, J.S. Zuback, et al., Additive manufacturing of metallic components-Process, structure and properties, Prog. Mater. Sci. 92 (2018) $112-224$.

[19] Z.T. Gan, G. Yu, X.L. He, S.X. Li, Numerical simulation of thermal behavior and multicomponent mass transfer in indirect laser deposition of Co-base ally on steel, Int. J. Heat Mass Transf. 104 (2017) 28-38.

[20] X. He, P.W. Fuerschbach, T. DebRoy, Heat transfer and fluid flow during laser spot welding of 304 stainless steel, J. Phys. D Appl. Phys. 36 (2003) 1388-1398.

[21] A. Bahrami, D.T. Valentine, B.T. Helenbrook, D.K. Aidun, Study of mass transport in autogenous GTA welding of dissimilar metals, Int. J. Heat Mass Transf. 85 (2015) 41-53.

[22] T. Mukherjee, H.L. Wei, A. De, T. DebRoy, Heat and fluid flow in additive manufacturing-Part I: Modeling of powder bed fusion, Comput. Mater. Sci. 150 (2018) 304-313.

[23] Z.Y. Li, G. Yu, X.L. He, et al., Numerical and experimental investigations of solidification parameters and mechanical property during laser dissimilar welding, Metals 8 (10) (2018) 799.

[24] H.L. Wei, J.W. Elmer, T. DebRoy, Origin of grain orientation during solidification of an aluminum alloy, Acta Mater. 115 (2016) 123-131.

[25] V. Voller, C. Prakash, A fixed grid numerical modelling methodology for convection-diffusion mushy region phase-change problems, Int. J. Heat Mass Transf. 30 (8) (1987) 1709-1719.

[26] A.D. Brent, V.R. Voller, K.J. Reid, Eethalphy-Porosity technology for modeling convection-diffusion phase change: application to the melting of a pure metal, Numer. Heat Transf. 13 (3) (1988) 297-318.

[27] P. Sahoo, T. DebRoy, M. McNallan, Surface tension of binary metal-surface active solute systems under conditions relevant to welding metallurgy, Metall. Mater Trans. B 19 (1998) 483-491.

[28] Z.T. Gan, G. Yu, X.L. He, S.X. Li, Surface-active element transport and its effect on liquid metal flow in laser assisted additive manufacturing, Int. Commun. Heat Mass 86 (2017) 206-214.

[29] S. Kou, Welding Metallurgy, John Wiley \& Sons, New York, 2003.

[30] Sarah J. Wolffa, Zhengtao Gan, Stephen Lin, Jennifer L. Bennett, Wentao Yan, Gregory Hyatt, Kornel F. Ehmann, Gregory J. Wagner, Wing Kam Liu, Jian Cao, Experimentally validated predictions of thermal history and microhardness in laserdeposited Inconel 718 on carbon steel, Addit. Manuf. 27 (2019) 540-551.

[31] Z. Gan, H. Li, S.J. Wolff, J.L. Bennett, G. Hyatt, G.J. Wagner, J. Cao, W.K. Liu, Datadriven microstructure and microhardness design in additive manufacturing using a self-organizing map, Engineering (2019). 